\title{
Effect of Ambient Temperature on Death Rate, Reject Rate, Dressing Percentage, and Economic Loss in Broilers During Transport to Slaughterhouse
}

\author{
๑ Enver Çavuşoğlu ${ }^{1 *}$, Roshan Riaz ${ }^{1}$
}

1Bursa Uludag University, Faculty of Veterinary Medicine, Department of Animal Science, 16059, Bursa

Received 24-04-2021 Accepted 12-05-2021

\begin{abstract}
The process of transporting broilers from the farm to the slaughterhouse is critical for animal welfare and for the production economy. During the transport process, the animal may suffer and die and this situation negatively affects animal welfare and profitability. The present study aimed to assess the impact of ambient temperature on the death rate, reject rate, and total economic loss in broilers during transportations in Turkey. The data of a total of 1,015,336 broilers transported for a two-year period were collected from a commercial abattoir. The average ambient temperature of the exact days of consignments was divided into three subgroups: Temperature (T), T1 (10.0-14.0 $\left.{ }^{\circ} \mathrm{C}\right), \mathrm{T} 2(14.1-19.0$ $\left.{ }^{\circ} \mathrm{C}\right)$, T3 $\left(19.1-24.0^{\circ} \mathrm{C}\right)$. The average death rates were $1.890 \%, 1.393 \%, 0.326 \%$, and reject rates were $1.151 \%, 1.611 \%$, and $1.441 \%$ found for T1, T2, and T3, respectively. Analysis of data showed the significant $(\mathrm{p}<0.001)$ effect of the ambient temperature on the death rate, and the higher impact was observed for $\mathrm{T} 1$ and lower for the T3. The reject rate among all groups was statistically significant $(\mathrm{p}=0.044)$, and the highest reject rate was found in T2 while the lowest reject rate was found in T1. The net economic loss due to rejected birds and death were 35,403 US\$ and 30,692 US\$, respectively, while the total economic loss was 66,095 US\$. In conclusion, the results of the present study showed that death rate, reject rates, and dressing percentage are impacted by the ambient temperature. Furthermore, death rates, rejection rates, and potential economic losses of the birds are linked with transportation from farm to the processing plant, and there is a need for management strategies to be refined through research by assessing the on-farm to processing plant risk factors, their linkages, as well as their potential contributions in Turkish integrated broiler production system.
\end{abstract}

Keywords: Broiler, transport, mortality, thermal stress, economic loss.

\section{Introduction}

Transportation of poultry is a required but stressful component of an integrated broiler production system. This stressor may cause discomfort and even death, which is more likely when animals have poor health conditions. Death rate of the poultry during transportation increased over the last decades, and researchers are working on various aspects to identify the different risk factors associated with the pre-slaughter death rate of the poultry. ${ }^{1}$ Various on-farm and pre-slaughter risk factors involved in the death of the birds are reported as the flock size, sex, age, on-farm mortality and culling, feed withdrawal and previous pathological condition, catching day, catching time, catching method, stocking density and size, vehicle, transportation time, season, environmental condition, transportation and lairage duration. ${ }^{2-4}$

Many conditions during transportation are critical risk factors, and a chicken's death is a response to these vital conditions. Thermal conditions during transportation have primary concern and drop the survival percentage of the transported poultry. ${ }^{5}$ These thermal conditions vary according to the geographical location, season, and trans-

\footnotetext{
* Corresponding author: ecavusoglu@uludag.edu.tr
} 
portation factors. A study in Brazil reported a death rate of $0.42 \%$ in summer and $0.28 \%$ in the winter season. ${ }^{5}$ Similarly, Whiting et al. ${ }^{6}$ found that the high summer temperature influences the poultry mortality in Canada. Similarly, Knezacek et al. ${ }^{7}$ found higher mortality rates during the most elevated cold weather and reported the death rate up to $1.4 \%$ in Canada. Another study in Italy ${ }^{8}$ reported higher death rates on arrival $(0.47 \%)$ in summer months where temperature remains above $25^{\circ} \mathrm{C}$ and Relative Humidity $(\mathrm{RH})$ more than $70 \%$. Vecerek et al.1 reported the highest death rate due to transport $(0.55 \%)$ in winter months than in summer $(0.30 \%)$. They founded a rise in death rate with increased transportation distance in all seasons except summer in the Czech Republic.

Another study ${ }^{9}$ reported $40 \%$ and $35 \%$ death on arrival due to thermal stress and injuries during catching, handling, and transportation of the poultry, respectively. These birds constitute an economic loss because they are deemed unsuitable for human consumption. Furthermore, they also demonstrated that the annual economic loss due to dead on arrival was $325,000 \$$. In Turkey, Aral et al. ${ }^{10}$ studied the influence of transportation time on body weight shrinkage and the death rate. They reported that the death rate ranges from $0.29 \%$ to $0.41 \%$ depending upon the transportation distance. Another study in Turkey ${ }^{11}$ declared the overall loss in the broiler chickens due to transportation length, age of the birds when slaughtering, and seasonal effects; and reported the significant influence of all these factors on the mortality rate due to transportation. Later the same study also noted that the death rate in long transport distances was similar in the winter and summer months.

In Turkey, the types of vehicles used for transportation of broilers do not regulate climatic conditions of chickens instantly. Most broiler chickens are shipped in trailers that wholly or partly open on the sides. The sides of the trailer may also be partially or entirely closed, depending on the environmental conditions. The circumstances under which the chickens travel are determined by the environmental conditions, ventilation of crates, and stocking density. Many factors have been reported to affect the mortality rates for broiler transportation. However, little information is available on the influences of ambient temperature on the mortality rates, reject rates and their economic impacts on Turkish transportation conditions and are needed to be addressed.

The present study aimed to investigate the effect of the daily ambient temperature on the death rate, reject rate due to transport of broilers to the slaughterhouse and the economic implications of these parameters under the commercial conditions in Turkey. Transportation thermal stress and injuries during catching, handling and transpor- tation are also the factors influencing the welfare and meat quality of broilers. Resolving the death rate and reject rate associated factors may decrease the welfare issues and economic losses in the poultry processing sector.

\section{Material and Methods}

The data of this study were collected from a commercial poultry slaughterhouse in Turkey. A total of 1,015,336 broilers were slaughtered during the evaluated period. The data were collected retrospectively, and the evaluation period was two years (2019-2020). Overall, the data of 153 trucks of broilers were assessed, and the death rate was calculated per truck of transport. To evaluate the effect of ambient temperature on death rate and rejects rate, the daily average ambient temperature of the exact days of consignments were categorized into three groups: Temperature 1 (10.0-14.0 $\left.{ }^{\circ} \mathrm{C}\right)$, Temperature $2\left(14.1-19.0^{\circ} \mathrm{C}\right)$, Temperature 3 (19.1-24.0 $\left.{ }^{\circ} \mathrm{C}\right)$. The temperature was assessed in Celsius $\left({ }^{\circ} \mathrm{C}\right)$. The number of animals transported in each subgroup were 394,$673 ; 157,93 ; 462,702$ for Temperature 1 , Temperature 2 , Temperature 3 , respectively. The daily average temperature as Celsius measured by the nearest meteorological station to the slaughterhouse was collected from the archives of the Meteorological Institute of the Ministry of Agriculture of Turkey. ${ }^{12}$ The distance from the meteorological station to the slaughterhouse was $5.1 \mathrm{~km}$.

Death rate was assessed by counting the number of animals that died from catching at the farm to the shackling (hanging chicken upside down for slaughter) process at the slaughterhouse and dividing the total number of dead chickens by the total number of birds loaded for transport. The death rate was counted for each transportation (Equation 1).

Death rate of each transport $=$ (number of animals died/ number of animals transported) $\times 100$

Some of the birds were rejected at the slaughterhouse for several reasons, such as pre-slaughter handling, during the slaughter process (mistakes caused by slaughter equipment), problems in the body of hens. The problems in carcass were emaciated carcasses, broken legs or wings, and other morphological deformities in carcasses. The reject rate was counted for each transportation (Equation 2).

Reject rate of each transport $=$ (number of animals slaughtered - number of carcasses rejected)/number of live animals slaughtered $\times 100(2)$

The dressing percentage was calculated per truck and it was calculated by counting the total live body weight of animals slaughtered and the total carcass weight exited from 
the slaughterhouse (Equation 3).

Dressing percentage $=$ (Total carcass weight of animals slaughtered / Total live body weight of animals slaughtered) $\times 100(3)$

After calculating the death and rejects rate, the total economic loss due to these animals (death and rejected) were calculated in US dollars. The cost of $1 \mathrm{~kg}$ live body weight of broilers at farm gate was 1.1 US \$ at the time of evaluation.

The normality of the data was tested by using Shapiro-Wilk test and the data were providing parametric test assumptions (normal distribution, homogeny of variances). Therefore, for multiple comparisons, One-Way ANOVA test was used; and Duncan test was performed as a post hoc test. The statistical significance level was accepted as $\mathrm{p}<0.05$. The statistical analysis was performed by the IBM SPSS Statistics 23 program. ${ }^{13}$

\section{Results}

The results of the death rate and reject rate as percentages are presented in Table 1. According to different ambient temperatures, the death rates were significantly different among each other $(\mathrm{p}<0.001)$. The death rate in the T1 group was highest among all groups $(1.890 \%)$. The dressing percentage among all groups was significantly different $(\mathrm{p}<0.001)$. The highest dressing percentage was found in the T3 group (78.013\%). When average body weight of animals before transport was compared among all groups, a significant difference was found $(\mathrm{p}<0.001)$. The lowest average body weight was found in the T3 group $(2.169 \mathrm{~kg})$. The reject rate between all groups was found significant $(p=0.044)$. The highest reject rate was found in T2 group Table 1. Death Rate, Reject Rate, Dressing Percentage and Body Weight according to different ambient Temperature (Mean \pm SEM).

\begin{tabular}{cccccc}
\hline $\begin{array}{c}\text { Temperature } \\
\left({ }^{\circ} \mathrm{C}\right)\end{array}$ & $\begin{array}{c}\text { Number } \\
\text { of Trucks }\end{array}$ & $\begin{array}{c}\text { Death Rate } \\
(\mathrm{n})\end{array}$ & $\begin{array}{c}\text { Reject Rate } \\
(\%)\end{array}$ & $\begin{array}{c}\text { Dressing } \\
\text { Percentage }\end{array}$ & $\begin{array}{c}\text { Average Body } \\
\text { Weight }(\mathrm{kg})\end{array}$ \\
\hline $\mathrm{T}^{*}$ & 62 & $1.890 \pm 0.273^{\mathrm{a}}$ & $1.151 \pm 0.056^{\mathrm{b}}$ & $77.133 \pm 0.123^{\mathrm{b}}$ & $2.466 \pm 0.037^{\mathrm{a}}$ \\
& & & & & \\
$\mathrm{T}^{*}$ & 24 & $1.393 \pm 0.182^{\mathrm{a}}$ & $1.611 \pm 0.142^{\mathrm{a}}$ & $77.212 \pm 0.233^{\mathrm{b}}$ & $2.584 \pm 0.060^{\mathrm{a}}$ \\
& & & & & \\
$\mathrm{T}^{*} 3^{*}$ & 67 & $0.326 \pm 0.027^{\mathrm{b}}$ & $1.441 \pm 0.138^{\mathrm{ab}}$ & $78.013 \pm 0.134^{\mathrm{a}}$ & $2.169 \pm 0.030^{\mathrm{b}}$ \\
& & $<0.001$ & 0.044 & $<0.001$ & $<0.001$ \\
\hline $\mathrm{p}$-value & & & & & \\
\hline
\end{tabular}

(1.611\%), while the lowest rate was found in $\mathrm{T} 1$ group $(1.151 \%)$.

The total number of transported animals, dead animals, and rejected animals are presented in Table 2. Overall, Table 2. The total number of transported, death, and rejected animals according to different ambient temperatures.

\begin{tabular}{cccc}
\hline & $\begin{array}{c}\text { Total Number } \\
\text { of Animal }\end{array}$ & $\begin{array}{c}\text { Total Number } \\
\text { of Death } \\
\text { Transported }\end{array}$ & $\begin{array}{r}\text { Total Number } \\
\text { of Rejects }\end{array}$ \\
\hline $\mathrm{T}^{*}$ & 394,673 & 7,621 & 4,392 \\
$\mathrm{~T}^{*}$ & 157,963 & 2,200 & 2,425 \\
$\mathrm{~T}^{*}$ & 462,702 & 1,579 & 6,957 \\
Total & $1,015,338$ & 11,400 & 13,774 \\
\hline
\end{tabular}

${ }^{*} \mathrm{~T} 1, \mathrm{~T} 2$, and $\mathrm{T} 3$ refers to ambient temperatures of $10.0-14.0{ }^{\circ} \mathrm{C} ; 14.1-$ $19.0^{\circ} \mathrm{C} ; 19.1-24.0^{\circ} \mathrm{C}$, respectively.

11,400 animals were dead, as well as 13,774 animals were rejected after the transportation.

The total live weight loss due to death and rejected animals; and the total economic loss due to death and rejected birds are presented in Table 3 . There was $27,903 \mathrm{~kg}$ of body weight loss due to death and $32,186 \mathrm{~kg}$ of body weight loss due to rejected animals, over among all evaluated animals. The economic loss due to death was $30,692 \$$, while the total economic loss due to rejected animals was 35,403 \$.

Table 3. Total body weight loss and economic loss due to death and rejected animals according to different ambient temperatures.

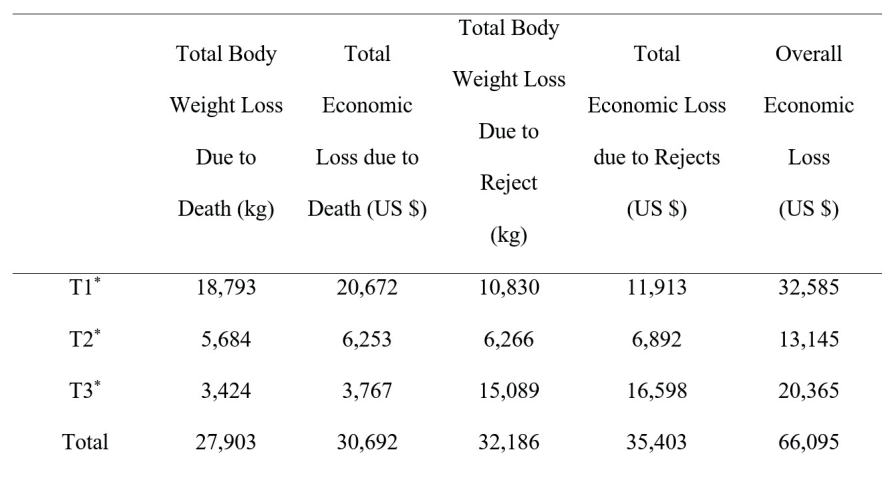

${ }^{\star} \mathrm{T} 1, \mathrm{~T} 2$, and T3 refers to ambient temperatures of $10.0-14.0{ }^{\circ} \mathrm{C} ; 14.1-$ 19.0 ${ }^{\circ} \mathrm{C}$; $19.1-24.0^{\circ} \mathrm{C}$, respectively.

Overall, the total economic loss due to death and rejected animals was 66,095 \$.

\section{Discussion}

Commercial broiler production is globally increasing every year to meet the nutritional requirements of the dramatically growing human population. In Turkey, approximately 258 million broilers were slaughtered in $2020 .{ }^{14}$ At slaughtering age, in an integrated commercial broiler production system, transportation of the broiler is an essential process, and the environmental conditions, mainly the temperature is a critical factor that alters the bird's physiology, meat 
quality, affects the welfare and have economic impacts. ${ }^{3,15-18}$ In this study, the maximum mortality was observed at T1, and the lowest mortality rate was found at T3 (Table 1). Similar to present results, Grilli et al. ${ }^{19}$ also reported the highest mortality rates during the cold season and lowest in the autumn season. However, the mortality values were lower compared to the present study. These variations might be due to the temperature differences at different seasons. The death rate because of thermal stress also varies based on the daily temperature fluctuations in different seasons. Vecerek et al. ${ }^{2}$ also reported the highest mortalities both in cold and hot months during the long transportation distances for processing. Similarly, in Turkey, Arikan et al. ${ }^{11}$ studied the seasonal effects on broiler mortality during transportation and reported higher mortalities during the summer. Later the authors noted that the death rate in winter months was like the summer period in long transport distances. During the winter season, birds closer to open sides suffer from cold and irregular air pattern within the vehicle, which results in higher temperature and suffocation, heart rate and respiration process gets affected. ${ }^{20,21}$ Furthermore, loss in the physiological ability of the birds to cope with these stressors results in the death of the birds. ${ }^{7}$ In Turkey, sometimes on cold days, to stabilize temperature within the vehicle for the bird, the sides of the trailers are covered with curtains to a certain extent. Even at the lower outside temperature, inner temperature rises, which is supportive to the birds. But a diverse pattern of airflow results in unfavourable temperature and humidity levels for certain birds, increasing the bird's core body temperature.

Vieira et al. ${ }^{5}$ studied the effects of different seasons on the bird's mortality during transport and reported the highest mortality in summer $(0.48 \%)$ than in winter $(0.28 \%)$. These differences might be due to the difference in transport conditions and temperature, which was higher than $22^{\circ} \mathrm{C}$, and the author stated that the pre-slaughter mortality during summer decreased when the controlled environment enhanced the lairage period. Similarly, other researchers suggested that in summers, a controlled environment lairage period of $3 \mathrm{~h}$ to $4 \mathrm{~h}$ should be provided to minimize the effect of heat stress during the transportation on the meat quality and death rate before slaughter. ${ }^{5}$ On the other hand, Dadgar et al. ${ }^{16}$ showed that a 20\% more negative impact of the two-hour lairage period occurred when birds were transported at $-8^{\circ} \mathrm{C}$ pre-slaughter. Bianchi et al. ${ }^{22}$ reported that pre-slaughter fasting duration is more critical concerning the death of the birds and found no impact of the lairage time on the pre-slaughter death rate of the birds. Warriss et al. ${ }^{23}$ reported that the temperature above $17^{\circ} \mathrm{C}$ is more detrimental to broilers during transport and causes more deaths than the temperature below $17^{\circ} \mathrm{C}$ up to $0^{\circ} \mathrm{C}$. Because evaporative cooling from the respiratory tract is an effective way of losing heat in poultry at high temperatures and the birds start panting when exposed to heat stress. However, evaporative processes may become less efficient or inefficient in high temperature and humidity. Like Warriss et al. ${ }^{23}$ experiment, since ambient temperatures are included in the analysis, they do not reflect the maximum temperature that the birds may have encountered on any given day during transport.

In the present study, $\mathrm{T} 3$ had the highest dressing percentage, and the lowest was observed in T1 (Table 1). Napper et al. ${ }^{17}$ studied the cellular mechanism to the thermal stress and reported that the cold and heat stress both initiate different cellular mechanism but ultimately results in the change in meat quality. At higher environmental temperatures, birds experience heat stress, resulting in mortality. ${ }^{24}$ But extreme cold (below $-8^{\circ} \mathrm{C}$ ) exposure to the birds lowers the blood glucose, core body temperature and induces liver shrinkage. ${ }^{16}$ Over and above that, manual catching and loading of broiler birds in cold weather are stress-causing, and the heart rate rises during these periods. Exposure of the birds to the cold environmental temperature results in high energy demand, and it increases the metabolism of the birds through glycogenesis and impacts on the meat quality and weight shrinkage. ${ }^{25}$ Aral et al. ${ }^{10}$ also showed that the highest weight shrinkage occurred in the heaviest birds during long-distance transport to the processing plant.

The effect of ambient temperature on reject rate was significant when all three groups compared. Similar to our results, Nijdam et al. ${ }^{15}$ founded the effect of the season and the ambient temperature during transportation on the bruises occurrence significant in the broilers. During transport, in thermal stress, birds show behavioural response, change their location and direction to resist, and sometimes climb up to each other, and that causes injuries. ${ }^{26}$ A low density of the birds in the pens during transportation allows the birds to regulate their body temperature. ${ }^{27}$ However, the higher space to the birds during the transportation is also directly related to the injuries during transport, which may increase the chance to reject rates. Contrarily, Dos Santos et al. ${ }^{28}$ also reported a non-significant effect of season and transportation timing on the bruises and injuries of broilers. These differences in results can be on-farm to processing plan management practices. In addition to the temperature and season, more attention should be paid to the birds during catching to reduce the chances of bruises, wings, and leg bone breakage. Birds encounter stresses during catching and loading and may undergo bruises, wing and leg bone fractures, and haemorrhages. ${ }^{29}$ Rough 
catching and handling of the broilers may result in injuries, and even can lead to death. ${ }^{21}$ Big flock size and higher catching time reduce labour efficiency. ${ }^{8}$ In Turkey, the birds are being caught manually, and the handlers catch and hold the birds either one or two legs in an inverted position and continue the catching till many birds are in their hands. After capturing, the birds are delivered into the crates or transferred to the other person who places the birds in the trucks. During this, manual catching, bending, handling, and transferring on a routine basis makes the works hectic, and inattentive handling leads to injuries and stress to the birds.

Furthermore, due to fear and stress, the birds flap their wings during handling, resulting in injuries and wing problems in some birds. Jacobs et al. ${ }^{18}$ reported that the wing fracture raised $1.76 \%$ after manual catching. Warriss et al. ${ }^{23}$ also noted that the day of catching affects the death rate, and this rise in death rate was not associated with temperature fluctuation within the week.

During the manual loading of the birds to the vehicles with the drawers, the birds can be trapped in the drawers during the closing, which can cause injuries. Kittelsen et al. ${ }^{30}$ examined at lairage time and reported wing injuries up to $1.4 \%$ of the flocks transported in modules containing drawers. A recent study reported that the high per crate density during transport increases the bruises percentage (3.37\%) in broilers. ${ }^{4}$ On processing plants from receiving to post-slaughter, injuries may occur, which may raise the reject rates of birds or their meat. ${ }^{21}$ All these bruises, traumas, wing and leg dislocations, sternum, and other bone fractures result welfare concerns to chickens, rising reject rates and ultimately economic loss. Overall, economic loss due to death and reject rates were also analysed, and it is emphatic that the reject rate in this study was higher than the mortality rates. Similarly, Aral et al. ${ }^{10}$ also reported a severe loss due to mortality and weight shrinkage during transportation.

\section{Conclusion}

In conclusion, on-farm catching, and handling and transportation conditions affect the death rate, reject rates, and overall economic loss. It is important to note that all these losses can be reduced by proper on-farm management and transportation practices. If the death rate and reject rate increase from the adjusted ranges, then the processing plant owners, veterinarians and supervisors must take detailed action and notify the supervisors to enhance the on-farm and transportation management conditions critically. Although the average daily temperature is analysed and humidity was not included in the study, it is suggested that to optimize the transportation condition, transportation tem- perature, humidity, and their impact on the welfare and mortality of the birds should be evaluated. Further, in Turkey, future studies should be organized to analyse the risk factors from on-farm loading to the end of the slaughter process and their interaction to minimize the pre-slaughter economic losses.

\section{Acknowledgements}

The authors would like to thank the staff of the slaughterhouse.

\section{References}

1. Vecerek V, Voslarova E, Conte F, Vecerkova L, Bedanova I. Negative trends in transport-related mortality rates in broiler chickens. Asian-Australasian J Anim Sci. 2016;29(12):1796-1804. doi:10.5713/ajas.15.0996

2. Vecerek V, Grbalova S, Voslarova E, Janackova B, Malena M. Effects of travel distance and the season of the year on death rates of broilers transported to poultry processing plants. Poult Sci. 2006;85(11):1881-1884. doi:10.1093/ps/85.11.1881

3. Caffrey NP, Dohoo IR, Cockram MS. Factors affecting mortality risk during transportation of broiler chickens for slaughter in Atlantic Canada. Prev Vet Med. 2017;147:199-208. doi:10.1016/j.prevetmed.2017.09.011

4. Saraiva S, Esteves A, Oliveira I, Mitchell M, Stilwell G. Impact of pre-slaughter factors on welfare of broilers. Vet Anim Sci. 2020;10. doi:10.1016/j.vas.2020.100146

5. Vieira FMC, Silva IJO, Barbosa Filho JAD, Vieira AMC, Broom DM. Preslaughter mortality of broilers in relation to lairage and season in a subtropical climate. Poult Sci. 2011;90(10):2127-2133. doi:10.3382/ ps.2010-01170

6. Whiting TL, Drain ME, Rasali DP. Warm weather transport of broiler chickens in Manitoba. II. Truck management factors associated with death loss in transit to slaughter. Can Vet J. 2007;48(2):148-154.

7. Knezacek TD, Olkowski AA, Kettlewell PJ, Mitchell MA, Classen HL. Temperature gradients in trailers and changes in broiler rectal and core body temperature during winter transportation in Saskatchewan. Can J Anim Sci. 2010;90(3):321-330. doi:10.4141/cjas09083

8. Petracci M, Bianchi M, Cavani C, Gaspari P, Lavazza A. Preslaughter mortality in broiler chickens, turkeys, and spent hens under commercial slaughtering. Poult Sci. 2006;85(9):1660-1664. doi:10.1093/ps/85.9.1660

9. Ritz CW, Webster AB, Czarick M. Evaluation of hot weather thermal environment and incidence of mortality associated with broiler live haul. J Appl Poult 
Res. 2005;14(3):594-602. doi:10.1093/japr/14.3.594

10. Aral Y, Arikan S, Akin AC, Yüksel Ç, Kuyululu K, Sakarya E. Economic Losses Due to Live Weight Shrinkage and Mortality during the Broiler Transport. Ankara Univ Vet Fak Derg. 2014; 61(3): 205-210. doi:10.1501/ Vetfak_0000002630

11. Arikan MS, Akin AC, Akcay A, et al. Effects of transportation distance, slaughter age, and seasonal factors on total losses in broiler chickens. Rev Bras Cienc Avic. 2017;19(3):421-428. doi:10.1590/1806-90612016-0429

12. Turkish Meteorology Institute Archives, 2021 (access date: February 2021, at: https://www.mgm.gov.tr/kurumsal/arsiv.aspx).

13. IBM Corp. Released 2015. IBM SPSS Statistics for Windows, Version 23.0. Armonk, NY: IBM Corp.

14. Turkish Statistical Institute, Poultry Production (access date April 2021 at: https:/data.tuik.gov.tr/Bulten/ Index? $\mathrm{p}=$ Poultry-Production-February-2021-37216.

15. Nijdam E, Arens P, Lambooij E, Decuypere E, Stegeman JA. Factors influencing bruises and mortality of broilers during catching, transport, and lairage. Poult Sci. 2004;83(9):1610-1615. doi:10.1093/ps/83.9.1610

16. Dadgar S, Lee ES, Leer TLV, Crowe TG, Classen HL, Shand PJ. Effect of acute cold exposure, age, sex, and lairage on broiler breast meat quality. Poult Sci. 2011;90(2):444-457. doi:10.3382/ps.2010-00840

17. Napper S, Dadgar S, Arsenault RJ, et al. Induction of tissue- and stressor-specific kinomic responses in chickens exposed to hot and cold stresses. Poult Sci. 2015;94(6):1333-1345. doi:10.3382/ps/pev046

18. Jacobs L, Delezie E, Duchateau L, Goethals K, Tuyttens FAM. Broiler chickens dead on arrival: Associated risk factors and welfare indicators. Poult Sci. 2017;96(2):259-265. doi:10.3382/ps/pew353

19. Grilli C, Stocchi R, Loschi AR, Conti F, Rea S. Survey on broiler pre-slaughter mortality in a commercial abattoir of central Italy. Ital J Food Saf. 2018;7(3):174180. doi:10.4081/ijfs.2018.5878

20. Zulkifli I, Al-Aqil A, Omar AR, Sazili AQ, Rajion MA. Crating and heat stress influence blood parameters and heat shock protein 70 expression in broiler chickens showing short or long tonic immobility reactions. Poult Sci. 2009;88(3):471-476. doi:10.3382/ps.200800287

21. Cockram MS, Dulal KJ. Injury and mortality in broilers during handling and transport to slaughter. Can J Anim Sci. 2018;98(3):416-432. doi:10.1139/cjas-20170076

22. Bianchi M, Petracci M, Cavani C. Effects of transport and lairage on mortality, liveweight loss and carcass quality in broiler chickens. Ital J Anim Sci. 2005;4(2):516-518. doi:10.4081/ijas.2005.2s.516

23. Warriss PD, Pagazaurtundua A, Brown SN. Relationship between maximum daily temperature and mortality of broiler chickens during transport and lairage. Br Poult Sci. 2005;46(6):647-651. doi:10.1080/00071660500393868

24. Quinteiro-Filho WM, Ribeiro A, Ferraz-de-Paula V, et al. Heat stress impairs performance parameters, induces intestinal injury, and decreases macrophage activity in broiler chickens. Poult Sci. 2010;89(9):19051914. doi:10.3382/ps.2010-00812

25. Dadgar S, Lee ES, Crowe TG, Classen HL, Shand PJ. Characteristics of cold-induced dark, firm, dry broiler chicken breast meat. Br Poult Sci. 2012;53(3):351-359. doi:10.1080/00071668.2012.695335

26. Vinco LJ, Archetti IL, Giacomelli S, Lombardi G. Influence of crate height on the welfare of broilers during transport. J Vet Behav Clin Appl Res. 2016;14:28-33. doi:10.1016/j.jveb.2016.06.006

27. Delezie E, Swennen Q, Buyse J, Decuypere E. The effect of feed withdrawal and crating density in transit on metabolism and meat quality of broilers at slaughter weight. Poult Sci. 2007;86(7):1414-1423. doi:10.1093/ ps/86.7.1414

28. dos Santos VM, Dallago BSL, Racanicci AMC, Santana P, Cue RI, Bernal FEM. Effect of transportation distances, seasons and crate microclimate on broiler chicken production losses. PLoS One. 2020;15(4). doi:10.1371/journal.pone.0232004

29. Prescott NB, Berry PS, Haslam S, Tinker DB. Catching and Crating Turkeys: Effects On Carcass Damage, Heart Rate, and Other Welfare Parameters. J Appl Poult Res. 2000;9(3):424-432. doi:10.1093/japr/9.3.424

30. Kittelsen KE, Granquist EG, Vasdal G, Tolo E, Moe RO. Effects of catching and transportation versus pre-slaughter handling at the abattoir on the prevalence of wing fractures in broilers. Anim Welf. 2015;24(4):387-389. doi:10.7120/09627286.24.4.387 